\title{
Comunicação em saúde sobre COVID-19 e Diabetes Mellitus em mídias sociais: verdadeiro e falso
}

\author{
Health communication about COVID-19 and Diabetes Mellitus in social media: true and false \\ Comunicación de salud sobre COVID-19 y Diabetes Mellitus en las redes sociales: verdadero y falso
}

\author{
Thalita da Silva Ribeiro ${ }^{1}$ (1) \\ Gabrielly Stechi ${ }^{1}$ (]) \\ Paola Cristina de Castro $^{1}$ (a) \\ Angelina Lettiere Viana ${ }^{1}$ (1)
}

1. Universidade de São Paulo, Escola de Enfermagem de Ribeirão Preto. São Paulo, SP, Brasil.

\section{Resumo}

Objetivos: Identificar em canais de veiculação midiática, os assuntos verdadeiros e falsos relacionados à COVID-19 e às pessoas com diabetes mellitus. Método: Pesquisa documental realizada em postagens no Twitter e nos sites da Sociedade Brasileira de Diabetes e do Ministério da Saúde e submetidas à análise temática e discutidas à luz das evidências científicas sobre o tema. Resultados: Das 110 postagens, 71 eram do Twitter, 31 do Ministério da Saúde e 8 da Sociedade Brasileira de Diabetes. As fake news correspondiam a 88 postagens; sete divulgavam informações sobre estudos não concluídos; seis eram notícias equivocadas; e nove verdadeiras. Os assuntos foram agrupados em alimentos e substâncias, condições de vida (socioeconômica e hábitos), medicações, COVID-19 e diabetes mellitus, gravidade e fatores de risco. Há excesso de desinformação com a finalidade de enganar e negar a realidade, dadas as disputas de saberes e poderes políticos, econômicos e ideológicos. Conclusão e implicações para a prática: A maior parte das postagens eram fake news. Em sendo as mídias sociais um lugar para a fácil disseminação de informações verdadeiras ou falsas, os cientistas e profissionais de saúde precisam se aproximar das comunidades virtuais dessas mídias e usá-las como ferramentas aliadas da comunicação em saúde.

Palavras-chave: Coronavirus; Diabetes Mellitus; Disseminação de Informação; Mídias Sociais; Comunicação em Saúde.

\section{Abstract}

Objectives: To identify true and false issues related to COVID-19 and to people with diabetes mellitus in media channels. Method: A documentary research study carried out in posts on Twitter and on the websites of the Brazilian Society of Diabetes and Ministry of Health, submitted to thematic analysis and discussed in the light of the scientific evidence on the topic. Results: Of the 110 posts, 71 were from Twitter, 31 by the Ministry of Health and 8 by the Brazilian Society of Diabetes. Fake news corresponded to 88 posts; seven disclosed information about unfinished studies; six were wrong news items; and nine were true. The topics were grouped into food products and substances, living conditions (socioeconomic and habits), medications, COVID-19 and diabetes mellitus, severity and risk factors. There is an excess of disinformation with the purpose of deceiving and denying reality, given the disputes over political, economic and ideological knowledge and powers. Conclusion and implications for the practice: Most of the posts were fake news. As the social media are a place for the easy dissemination of true or false information, scientists and health professionals need to approach the virtual communities of these media and use them as allied tools for communication in health.

Keywords: Coronavirus; Diabetes Mellitus; Information Dissemination; Social Media; Health Communication.

\section{Resumen}

Objetivos: Identificar cuestiones verdaderas y falsas relacionadas con el COVID-19 y personas con diabetes mellitus en los canales de comunicación. Método: Investigación documental realizada en publicaciones en Twitter y en los sitios web de la Sociedad Brasileña de Diabetes y el Ministerio de Salud, sometida a análisis temático y discutida a la luz de la evidencia científica sobre el tema. Resultados: De las 110 publicaciones, 71 fueron de Twitter, 31 del Ministerio de Salud y 8 de la Sociedad Brasileña de Diabetes. Las noticias falsas correspondieron a 88 publicaciones; siete revelaron información sobre estudios inconclusos; seis fueron noticias equivocadas; y nueve verdaderas. Los temas se agruparon en alimentos y sustancias, condiciones de vida (socioeconómicas y de hábitos), medicamentos, COVID-19 y diabetes mellitus, gravedad y factores de riesgo. Existe un exceso de desinformación con el propósito de engañar y negar la realidad, dadas las disputas sobre conocimientos y poderes políticos, económicos e ideológicos. Conclusión e implicaciones para la práctica: La mayoría de las publicaciones eran noticias falsas. Dado que las redes sociales son un lugar para la fácil difusión de información verdadera o falsa, los científicos y los profesionales de la salud deben acercarse a las comunidades virtuales de estos medios y utilizarlos como herramientas aliadas para la comunicación en salud.

Palabras clave: Coronavirus; Diabetes Mellitus; Diseminación de la Información; Medios de Comunicación Social; Comunicación en Salud
Autor correspondente:

Thalita da Silva Ribeiro.

E-mail: thalita.sribeiro@outlook.com

Recebido em 13/09/2021.

Aprovado em 05/01/2022.

DOI:https://doi.org/10.1590/2177-9465-EAN-2021-0358 


\section{INTRODUÇÃO}

No final de 2019, na cidade de Wuhan, na China, foi identificado um novo coronavírus causador da Síndrome Respiratória Aguda Grave - Coronavírus 2 (Severe Acute Respiratory Syndrome Coronavirus 2) denominado SARS-CoV2. Este vírus é o agente responsável por ocasionar a doença do coronavírus (Corona Virus Disease), intitulada COVID-19. A transmissão do vírus ocorre por meio do contato com gotículas respiratórias, o que pode justificar a alta transmissibilidade desse agente etiológico. ${ }^{1}$ De acordo com dados da Organização Mundial da Saúde (OMS), disponibilizados em 12 de novembro de 2021, havia 251.788 .329 casos confirmados da doença e 5.077.907 mortes no mundo. ${ }^{2}$ Até 12 de novembro de 2021, segundo dados disponibilizados pelo Ministério da Saúde (MS), o Brasil havia registrado cerca de 21.909.298 casos confirmados da doença e 610.036 óbitos. $^{3}$

Até o momento, sabe-se que a letalidade da doença pode variar de acordo com a faixa etária e segundo determinadas condições clínicas, ${ }^{1}$ tais como: idade avançada, doença pulmonar obstrutiva crônica, asma e dependência de oxigênio, problemas cardíacos graves, hipertensão não controlada, diabetes mellitus, doenças cromossômicas ou estado de fragilidade imunológica, insuficiência renal crônica avançada, gestação de alto risco, obesidade grave (Índice de Massa Corporal - IMC > 40) e doenças hepáticas. Essas condições agravam a saúde dessas pessoas o que torna necessária a internação em Unidade de Terapia Intensiva (UTI) e/ou o uso ventilação mecânica. ${ }^{4-6}$

Entre os indivíduos hospitalizados no Brasil, observa-se uma maior prevalência de pessoas com comorbidades em comparação com a população geral. A prevalência de hospitalização de indivíduos com Síndrome Respiratória Aguda Grave (SRAG) com Diabetes Mellitus (DM) foi de $25 \%$ e estima-se que $7,3 \%$ das pessoas que foram a óbito possuíam DM. ${ }^{1}$

A relação entre COVID-19 e DM é complexa, podendo-se considerar duas vertentes que explicam o agravamento da doença. A primeira consiste em fatores como o estado próinflamatório e hipercoagulável, hiperglicemia e comorbidades (hipertensão arterial, doença cardiovascular, doença renal crônica e obesidade). Por outro lado, uma infecção grave por COVID-19 e seu tratamento com esteroides podem ter um impacto negativo sobre a DM e o agravamento da hiperglicemia pode, por sua vez, afetar adversamente o curso da COVID-19. ${ }^{7}$

Como resultado do avanço e disseminação da COVID-19 pelo mundo, aumentou a circulação de informações que evidenciaram um espaço de disputa pelo monopólio da verdade e que ganha novos contornos no contexto digital, visto que as pessoas compartilham inadvertidamente os conteúdos que ditam uma certa visão de mundo em que acreditam. ${ }^{8}$ Muitas dessas comunicações em saúde podem ser equivocadas ${ }^{9}$ e denominadas de fake news ${ }^{10,11} \mathrm{e}$ podem gerar impactos negativos para a saúde coletiva.

Em decorrência desse montante de informações, a OMS passou a utilizar o termo "infodemia", referindo-se ao excesso de informações, precisas ou não, que dificultam a busca por fontes confiáveis. ${ }^{12,13}$ Dessa forma, com o objetivo de divulgar mensagens corretas, a OMS lançou uma plataforma de informação. Tal medida evidencia uma epidemia global de desinformação, ${ }^{14}$ ou seja, de informações falsas ou imprecisas cuja intenção deliberada é enganar. ${ }^{13}$ No contexto pandêmico da COVID-19, a infodemia possibilita a disseminação da desinformação, fenômeno denominado pela Organização das Nações Unidas para a Educação, a Ciência e a Cultura (UNESCO) por desinfodemia. ${ }^{15}$

No Brasil, com o objetivo de combater as fake news sobre a saúde, o MS viabilizou um número de telefone de WhatsApp para que a população enviasse mensagens ou fotos que viram ou receberam pelos meios de comunicação, de maneira a averiguar se as informações são verdadeiras ou não. Além disso, o MS disponibilizou uma página em seu site com publicações sobre notícias avaliadas quanto à sua veracidade, ${ }^{16}$ embora muitas pessoas em vez de utilizá-las como canais de comunicação oficiais, utilizam com maior frequência as redes sociais como fontes confiáveis. ${ }^{17}$

Frente a esse contexto de propagação das chamadas Fake News e às lacunas de conhecimento acerca da COVID-19 e sua relação com a DM, faz-se necessário identificá-las e combatêlas. ${ }^{18}$ Assim, o objetivo do presente estudo foi identificar em canais de veiculação midiática, os assuntos verdadeiros e falsos relacionados à COVID-19 e às pessoas com diabetes mellitus. Portanto, questiona-se: Quais são as notícias que estão sendo veiculadas acerca do DM e da COVID-19? As informações contidas nas notícias são pautadas em fontes veiculadas por órgãos competentes ou por evidências científicas?

\section{MÉTODO}

Pesquisa documental e bibliográfica que buscou avaliar documentos do tipo primários, ou seja, não submetidos a tratamentos analíticos ou científicos, tais como: reportagens de jornal, filmes, fotografias dentre outros. ${ }^{19}$ As fontes para extração de dados foram provenientes de arquivos público ${ }^{20}$ nas mídias digitais: Twitter, Sociedade Brasileira de Diabetes (SBD) e Ministério da Saúde (MS). A escolha pela plataforma do Twitter deu-se por se tratar de uma das maiores plataformas digitais que permitem envio de textos e por ter conectividade com outras plataformas como o Facebook e o Instagram. ${ }^{21}$ Já a escolha dos sites da SBD e do MS justifica-se por configurarem entidades da área da saúde e da temática em estudo (COVID-19 e DM) que estão empenhadas no combate à desinformação.

Na primeira etapa do estudo, procedeu-se ao levantamento de dados nas mídias escolhidas no período de janeiro a junho 2021. No Twitter, a coleta de dados foi realizada por meio da utilização da função de "busca avançada", o que possibilitou a seleção dos filtros e das palavras-chave. Os filtros selecionados foram: qualquer pessoa, localização em qualquer lugar, incluir respostas e tweets originais, incluir tweets com links e, por fim, foram selecionados o mês de dezembro de 2019 e os meses de janeiro a março e de setembro a dezembro de 2020. No campo das palavras-chaves, foram digitadas as palavras "coronavírus" e "diabetes".

No Twitter, é importante destacar que o recorte temporal foi delimitado pelo extenso quantitativo de tweets encontrados 
no período de dezembro de 2019 a dezembro de 2020, o que tornaria a realização desta pesquisa incompatível com o tempo disponível e com os recursos humanos, assim, optou-se pelos meses iniciais e finais ao longo de um ano do início da pandemia.

Para realizar o levantamento das informações da SBD, fo utilizado o site do Google e, no campo de buscas o termo "SBD e coronavírus" e utilizado o quinto link da página. A página da SBD estava intitulada "SBD - Diabetes na era COVID-19"22 e no topo do site da SBD, constam algumas palavras-chave com link direto para o assunto desejado e, no presente estudo, utilizou-se duas palavras-chave. A primeira denominada "COVID-19 e Diabetes" direcionava para a página intitulada nota de esclarecimento sobre a COVID-19. ${ }^{23} \mathrm{~A}$ segunda intitulada "Perguntas frequentes" direcionava para a página "Perguntas frequentes: dúvidas frequentes sobre COVID-19 e diabetes."24 Esses são ambientes com informações sobre os desdobramentos da COVID-19 em pessoas com DM com perguntas e respostas.

Para a coleta de dados das informações do MS, foi utilizado o site do Google e, no campo de buscas, foi inserida a frase "ministério da saúde fato ou fake" e utilizado o primeiro link da página de buscas que direciona para página oficial do MS.$^{25}$ Nessa página é possível utilizar um campo de filtro para as buscas dos conteúdos, tais como: título, data de início, data final e número de notícias por abas que serão visualizadas. No campo do título utilizou-se a palavra "coronavírus" e como recorte temporal o período compreendido entre dezembro de 2019 a dezembro de 2020.

Os textos das notícias foram armazenados em planilhas do Excel, além disso, optou-se por tirar prints dos conteúdos que a priori tenham provocado dúvidas quanto à veracidade dos fatos apresentados. Após o armazenamento das notícias, procedeu-se à leitura e à aplicação dos critérios de inclusão e exclusão. Os critérios de inclusão foram: postagens contendo as palavras COVID-19, corona, covid, diabetes, DM e publicações contendo recomendações ou cuidados que as pessoas com ou sem DM devem tomar em relação ao coronavírus.

As postagens não relacionadas exclusivamente às pessoas com DM foram incluídas, pois os conteúdos destinavam-se aos cuidados gerais que poderiam ser utilizados também pelas pessoas com DM como, por exemplo, cuidados alimentares para prevenção da COVID-19. Foram excluídas as notícias que envolvessem crianças e gestantes, em idiomas diferentes do Português, Inglês, Espanhol, memes, charges e informações com teor político ou aquelas que não possuíam relação com a saúde.

Após a seleção das notícias e a organização do material, procedeu-se à análise temática de conteúdo com a leitura compreensiva e exaustiva para impregnação do material (visão do conjunto e apreensão das particularidades), à exploração do material (identificação dos núcleos de sentido e das temáticas mais amplas) e, por fim, à elaboração da síntese interpretativa que dialoga com o objetivo, com a questão norteadora e com o quadro teórico conceitual. ${ }^{26}$

O quadro conceitual foi sustentado pela produção científica atual sobre o tema (COVID-19 e DM) com buscas em bases de dados científicas e em materiais publicados pela SBD e pelo MS. Esse quadro teórico foi utilizado para analisar e classificar as informações como verdadeiras ou falsas. Ademais, foi verificado se as notícias veiculadas possuíam fontes pautadas em órgãos competentes ou em artigos científicos.

Não foi necessário submeter o estudo no Comitê de Ética em Pesquisa visto que as informações veiculadas no Twitter, SBD e MS estão em espaço público, aberto e acessível para a população. No entanto, em relação às questões éticas foram seguidas as recomendações sobre anonimato das pessoas, fidedignidade das informações e o respeito à política de uso do Twitter.

\section{RESULTADOS}

A Figura 1 ilustra o processo de seleção das notícias que compuseram a amostra do presente estudo de acordo com os critérios de elegibilidade e os motivos das exclusões. No Twitter foram recuperadas 7.523 postagens e selecionadas 71 . No site da SBD, na aba "Diabetes na era COVID-19", ${ }^{23}$ na nota de esclarecimento sobre a COVID-19, obtiveram-se 24 perguntas e respostas e, na aba intitulada "Perguntas frequentes: dúvidas frequentes sobre COVID-19 e diabetes", foram obtidas 11 perguntas e respostas. Das 35 notícias, 10 estavam duplicadas e foram selecionadas oito perguntas. No site do MS, foi possível recuperar 83 notícias e, destas, 31 foram selecionadas. Dessa forma, foram analisadas 110 notícias.

As perguntas e as respostas selecionadas no site da SBD foram: "Por que as pessoas com diabetes estão no grupo de maior risco de infecção em relação ao COVID-19?"; "As pessoas com diabetes estão no grupo de maior risco para evoluir com as formas graves da doença?"; "O risco de complicações da COVID-19 é maior tanto para quem tem diabetes tipo 1 quanto tipo 2?"; "Existe algum medicamento para o tratamento da infecção pelo coronavírus? Isso é diferente para as pessoas com diabetes?"; "Existe algum tratamento com remédios alternativos que beneficiem ou previnam que pessoas com diabetes possam se infectar por coronavírus?"; "Tomar vitamina C ou qualquer outro tipo de suplemento diminui o risco de COVID-19?"; "Qual medicamento não deve ser usado por pessoas com diabetes, com suspeita ou confirmação de infecção pelo coronavírus?" "As pessoas com diabetes que tomam Captopril, Enalapril, Losartana, Aspirina ou Pioglitazona devem suspender o tratamento?".

$\mathrm{Na}$ análise de conteúdo as notícias foram organizadas em cinco categorias temáticas: "alimentos e substâncias", "condição socioeconômica e hábitos de vida", "medicações", "COVID-19 e DM" e "gravidade e fatores de risco". A avaliação do conteúdo veiculado foi realizada com base no quadro teórico científico e será melhor explorado na seção de discussão do presente estudo. Além disso, as informações foram avaliadas quanto ao conteúdo veiculado, ou seja, se elas se tratavam de informações falsas (fake news), em estudo, equivocadas ou verdadeiras (Tabela 1).

As notícias denominadas equivocadas são informações corretas que foram distorcidas, tanto pelo exagero ao relatar o assunto quanto pela divulgação parcial, prejudicando a correta 
Twitter ( $\mathrm{n}=7523)$

Ministério da Saúde ( $\mathrm{n}=83$ )

Sociedade Brasileira de Diabetes $(n=35)$

Total: 7641
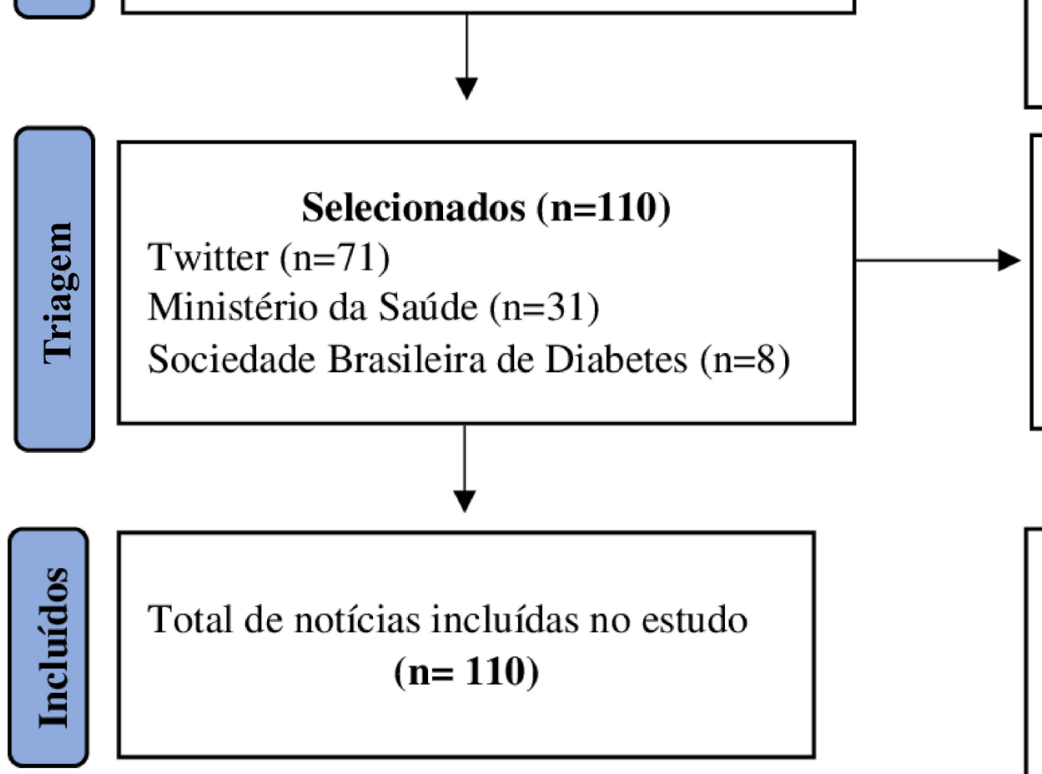

Total de notícias incluídas no estudo

$$
(\mathbf{n}=110)
$$

Figura 1. Fluxo do processo de seleção das notícias. Ribeirão Preto, São Paulo, Brasil, 2021.

interpretação do fato. Como exemplo, tem-se uma notícia veiculada de que a vitamina $D$ previne a diabetes e que, nas mortes por COVID-19, observou-se deficiência dessa vitamina.

As perguntas disponibilizadas no site da SBD guardam relação com as notícias falsas veiculadas nas mídias sociais, porém não foram identificadas. As respostas divulgadas pela SBD tinham como objetivo esclarecer e divulgar as melhores informações sobre os desdobramentos da COVID-19 em pessoas com DM. Assim, no presente estudo foram consideradas as respostas e essas foram classificadas como verdadeiras. No site do MS é disponibilizada a notícia e o esclarecimento sobre o conteúdo veiculado. Portanto, no estudo foram consideradas as notícias analisadas pelo MS e essas foram classificadas como falsas. Vale destacar que o MS também classifica as notícias em verdadeiras ou falsas.

Entre as notícias veiculadas é possível observar que a maior parte $(80 \%)$ das postagens eram fake news $(n=88)$ e somente nove notícias eram verdadeiras. Observou-se que nenhuma das notícias possuía a fonte, ou seja, referência de órgãos competentes ou de artigos; alguns conteúdos faziam alusão a opiniões de profissionais da saúde, muito embora não tenham sido identificados pelo nome, especialidade ou local de atuação. Em relação às informações desmentindo as fake news no site do MS e à resposta no site da SBD também não possuíam as fontes. O Quadro 1 apresenta alguns exemplos das notícias veiculadas no Twitter e no MS classificadas como fake news.

\section{DISCUSSÃO}

Os resultados do presente estudo evidenciam que $80 \%$ das notícias veiculadas eram falsas e sem fontes de consulta. A literatura aponta que as notícias falsas são muito mais compartilhadas do que as informações baseadas em evidências científicas. ${ }^{27,28}$ Esse fenômeno se amplifica com as redes e as mídias sociais por serem os principais meios de comunicação em massa e por permitirem uma rápida disseminação das informações. ${ }^{11}$

Nesse contexto, os indivíduos passam a ser propagadores e interlocutores dessas informações. Contudo, é importante que as pessoas saibam diferenciar as informações verdadeiras das falsas, bem como aquelas baseadas em evidências científicas das opiniões. ${ }^{29}$ No entanto, para a população pode ser muito difícil distinguir entre as notícias verdadeiras e falsas. ${ }^{30}$

Com o advento da pandemia da COVID-19, muitas incertezas e dúvidas surgiram a respeito da doença e as pessoas buscaram informações nas mídias sociais. Frente a essa busca e ao crescente número de informações falsas em circulação acerca da COVID-19, 
Tabela 1. Classificação das notícias de acordo com a categoria temática e os núcleos de sentidos. Ribeirão Preto, São Paulo, Brasil, 2021.

\begin{tabular}{|c|c|c|c|c|c|c|c|}
\hline \multirow{2}{*}{$\begin{array}{l}\text { Categoria } \\
\text { Temática }\end{array}$} & \multirow[t]{2}{*}{ Núcleos de sentido } & \multicolumn{4}{|c|}{ Twitter (n=71) } & \multirow{2}{*}{$\begin{array}{c}\begin{array}{c}\text { SBD } \\
(n=8)\end{array} \\
\text { VE }\end{array}$} & \multirow{2}{*}{$\begin{array}{c}\begin{array}{c}\text { MS } \\
(n=31)\end{array} \\
\text { FA }\end{array}$} \\
\hline & & FA & $\mathrm{EE}$ & PR & VE & & \\
\hline \multirow{6}{*}{$\begin{array}{l}\text { Alimentos e } \\
\text { substâncias }\end{array}$} & Comidas & 05 & & & & & 13 \\
\hline & Vitaminas & 01 & & 02 & & 02 & 04 \\
\hline & Veneno de cobra & 01 & & & & & \\
\hline & Materiais de limpeza & 01 & & 01 & & & 01 \\
\hline & Óleo de canabidiol/maconha & 01 & 01 & & & & \\
\hline & Óleo consagrado & & & & & & 01 \\
\hline \multirow{4}{*}{$\begin{array}{l}\text { Condição } \\
\text { socioeconômica } \\
\text { e hábitos de vida }\end{array}$} & Favorecidos economicamente & 12 & & & & & \\
\hline & Nacionalidade & 01 & & & & & \\
\hline & Atividade física & 01 & & & & & \\
\hline & Religiosidade & 04 & & & & & \\
\hline \multirow{3}{*}{ Medicações } & Diabetes e Hipertensão & 01 & & 01 & & & \\
\hline & Cloroquina/coquetel antiviral & 02 & & & & 01 & 04 \\
\hline & Fitoterápico/outros & 01 & 01 & & 01 & 03 & \\
\hline \multirow{8}{*}{ COVID-19 e DM } & Cirurgia & & 01 & & & & \\
\hline & Vacina & 01 & & & & & 03 \\
\hline & Indústria farmacêutica & 01 & & & & & \\
\hline & Máscara & 01 & & & & & 02 \\
\hline & Tipo sanguíneo & 01 & & & & & \\
\hline & Inoculação viral & 01 & & & & & \\
\hline & Coronavírus provoca diabetes & & 03 & & & & \\
\hline & Origem & 05 & & & & & 03 \\
\hline \multirow{4}{*}{$\begin{array}{l}\text { Gravidade e } \\
\text { fatores de risco }\end{array}$} & Glicose & & 01 & & & & \\
\hline & Insulina & 01 & & & & & \\
\hline & Comorbidades & 14 & & 02 & & 03 & \\
\hline & Pneumonia & 01 & & & & & \\
\hline Total & & 57 & 07 & 06 & 01 & 08 & 31 \\
\hline
\end{tabular}

FA: falsos EE: em estudo PR: precipitada VE: verdadeiro

os órgãos de saúde e a imprensa se mobilizaram com o objetivo de desmentir essas informações sem fundamentação. ${ }^{31} \mathrm{~A}$ pandemia da COVID-19 evidenciou a urgência de se trabalhar nas formas de circulação do conhecimento, no diálogo com a sociedade, para fortalecer o reconhecimento social das ciências. ${ }^{32}$ Dessa forma, evidencia-se que as mídias também possuem fundamental importância na propagação da educação em saúde e como mediadora da comunicação em saúde. ${ }^{27}$

Na análise qualitativa das notícias, depreenderam-se cinco categorias. Na discussão das notícias elencadas nas categorias foram selecionadas aquelas de maior relevância na temática, visto o quantitativo extenso de notícias. É importante destacar que a maioria das notícias escolhidas versam sobre as fake news.
$\mathrm{Na}$ primeira categoria temática intitulada "alimentos e substâncias", os assuntos mais abordados versavam sobre a utilização de alimentos e substâncias com a promessa de que poderiam prevenir e curar a COVID-19 e algumas notícias acerca da cura para o diabetes e de outras doenças. Os alimentos e substâncias citados foram: chás imunológicos, whisky e mel, beber água de 15 em 15 minutos, café, água de coco, chás em geral, água especial desenvolvida em laboratório, injeção de antígeno de veneno de cobra, uso do óleo de Canabidiol, fumar cigarro de maconha, uso de vitaminas $C$ e D e ingestão de alvejante. Todas essas notícias foram classificadas como falsas uma vez que na literatura não existe um medicamento específico para tratar COVID-19 ou curar a COVID-19 e DM. ${ }^{25,33}$ 
Quadro 1. Relação de assuntos Fake News encontradas em três plataformas de veiculação de informações. Ribeirão Preto, São Paulo, Brasil, 2021.

\begin{tabular}{|c|c|c|c|}
\hline \multirow{2}{*}{ Categoria Temática } & \multirow{2}{*}{ Notícia } & \multicolumn{2}{|c|}{ Mídia } \\
\hline & & MS & Twitter \\
\hline Alimentos e substâncias & $\begin{array}{l}\text { Receita de coco que cura coronavírus } \\
\text { A vitamina D também ajuda a prevenir diabetes, ataque cardíaco e } \\
\text { derrame. As pessoas que morreram com o Coronavírus tinham deficiência } \\
\text { de vitamina D } \\
\text { Eu juro, pelo que tenho "ouvido", água de coco é a resposta para: } \\
\text { diabetes, doença renal, doença hepática, hipertensão, controlar o } \\
\text { colesterol, coronavírus, droga: encontramos o elixir da vida! } \\
\text { Café previne o coronavírus } \\
\text { Chá de limão com bicarbonato quente cura coronavírus } \\
\text { Óleo consagrado para curar coronavírus } \\
\text { Vitamina C cura coronavírus, que veio dos animais, e água com limão que } \\
\text { cura câncer } \\
\text { Vídeo - vitamina D e a prevenção do novo coronavírus }\end{array}$ & $\begin{array}{l}x \\
x \\
x \\
x \\
x\end{array}$ & $\mathrm{x}$ \\
\hline $\begin{array}{l}\text { Condição } \\
\text { socioeconômica e } \\
\text { hábitos de vida }\end{array}$ & $\begin{array}{l}\text { Tanto o coronavírus quanto o diabetes são doenças de alto poder } \\
\text { aquisitivo }\end{array}$ & & $x$ \\
\hline
\end{tabular}

O uso da maconha e o óleo de Canabidiol (CBD) pode em alguns casos fortalecer o sistema imunológico e colaborar no tratamento de algumas doenças, o que poderia ajudar no manejo do COVID-19 e DM. O extrato bruto do CBD ocasiona uma redução dos níveis de secreção de interleucina 6 (IL-6) e interleucina 8 (IL-8), e as altas concentrações tanto do CBD quanto do tetrahidrocanabidiol (THC) foram avaliadas em relação às suas características anti-inflamatórias. Nesse estudo, o THC demonstrou baixa ação anti-inflamatória, ao passo que o CBD apresentou atividade considerável na diminuição dos níveis secretados de IL-6 e IL-8 nas células epiteliais pulmonares. A COVID-19 provoca um efeito no organismo conhecido como tempestade de citocinas, sobretudo do tipo IL-8 nas formas graves da COVID-19. Diante desse cenário, é importante mencionar que resultados sobre a ação anti-inflamatória do CBD foram outrora observados em pesquisa realizada in vitro, ${ }^{34}$ apresentando, portanto, embasamento científico. No entanto, não há estudo em seres humanos o que requer mais estudos acerca da temática.

Em relação ao uso das vitaminas $C$ e $D$, as notícias veiculavam seu uso como fonte de prevenção da contaminação pelo coronavírus ou como fonte de prevenção e cura da forma grave da doença. No que tange às duas vitaminas, no cenário da COVID-19, foi constatado que a vitamina $D$ pode prevenir a tempestade de citocinas em pacientes com a COVID-19 e, paralelamente, observou-se um mau prognóstico da doença nas pessoas com deficiência dessa vitamina. Contudo, não se sabe ainda os níveis de vitamina $\mathrm{D}$ no plasma que atua como um fator de risco para COVID-19. A vitamina $C$ age de maneira atenuante das respostas imunológicas excessivas em indivíduos com COVID-19, tendo como um desses mecanismos prevenir a hiperativação das células imunes por meio da inibição do gliceraldeído 3-fosfato desidrogenase (GAPDPH). Essa inibição poderia reduzir a produção de trifosfato de adenosina e a ativação de células da imunidade. Dessa forma, não existem ainda estudos que possam comprovar as relações e os benefícios diretos das vitaminas C e D no curso da COVID-19. ${ }^{35}$

No que diz respeito à relação entre a $\mathrm{DM}$ e a vitamina $\mathrm{D}$, estudos preliminares sugerem que ela atua como um fator protetor para a DM tipo 1, contudo ensaios clínicos demonstraram baixa potência em seus resultados, evidenciando que há necessidade de mais estudos para comprovar e avaliar o impacto da suplementação vitamínica na prevenção ou proteção contra o DM. ${ }^{36}$

A segunda categoria denominada "condição socioeconômica e hábitos de vida" engloba as classes sociais mais favorecidas, a nacionalidade, a atividade física e a religiosidade. Alguns assuntos abordados associavam que as pessoas com melhores condições econômicas têm maior risco de desenvolver a COVID-19. Um estudo que aborda as relações da pandemia no Brasil, no contexto das vulnerabilidades relacionadas ao gênero, à raça e à classe, demonstrou que apesar dos primeiros infectados no país possuírem uma condição econômica mais privilegiada, a infecção pelo vírus se dá de igual forma para todas as pessoas, ${ }^{37}$ logo essa notícia se caracteriza como falsa, pois pessoas com condições econômicas das mais diversas estão suscetíveis à contaminação pelo coronavírus e ao desenvolvimento da COVID-19. Apesar de todas as pessoas estarem suscetíveis à contaminação, é importante refletir que a determinação social do processo saúde-doença pode influenciar 
na disseminação da infecção, na morbidade e na mortalidade associado à COVID-19 e, especialmente no Brasil, a fatores relacionados à desigualdade social e às iniquidades ao acesso aos serviços de saúde. ${ }^{38}$

A religião foi utilizada como justificativa para os acontecimentos atuais. Assim, o vírus teria sido enviado por uma entidade divina como castigo ou essa entidade seria a única forma de cura da COVID-19. Ainda não existem dados científicos que relacionem certas práticas religiosas e cura na COVID-19. No entanto, não se pode ignorar que, em certas situações, a prática e a crença baseada na fé promoveram alguns benefícios à saúde. Porém, ainda não há estudos relacionando essa interface entre a COVID-19 e DM. Logo, acredita-se que pelo grande poder que a religião tem de influenciar as pessoas, esta pode ser utilizada como recurso para promoção da educação em saúde contra o COVID-19 e DM. ${ }^{39}$

A terceira categoria versa sobre "medicações" para DM e hipertensão, cloroquina/coquetel antiviral e fitoterápicos/outros. Um tópico que merece destaque se refere à descontinuidade do uso dos medicamentos para DM e hipertensão, o que não é recomendado pelos especialistas a não ser que a pessoa passe por uma criteriosa avaliação com o profissional de saúde. Acredita-se que tal notícia falsa tenha sido veiculada em decorrência de estudos que estão sendo realizados para averiguar se existe uma relação entre os inibidores da Enzima Conversora da Angiotensina (ECA) na evolução da COVID-19, logo a descontinuação desses medicamentos sem antes uma avaliação profissional pode ocasionar malefícios à saúde dessa população. ${ }^{40}$

Uma revisão sistemática com 234 estudos identificou que existem evidências que corroboram para a eficácia do uso da cloroquina como tratamento para COVID-19, entretanto o uso desse fármaco é algo experimental, necessitando de aprovações dos comitês de ética em pesquisa com seres humanos e de revisão por pares desses estudos. Alguns artigos só avaliaram a eficiência e a eficácia da cloroquina no sentido de reprimir a replicação viral in vitro. Dessa forma, há necessidade de estudos mais aprofundados para avaliar a aplicabilidade e a segurança clínica. ${ }^{25,41-43}$

A notícia veiculada sobre fitoterapia se refere às cápsulas de diabetina para cura da COVID-19 e para a diabetes. Pesquisas científicas sobre a diabetina não foram encontradas nas bases de dados, entretanto, na literatura cinzenta (site de buscas Google), identificaram-se propagandas dessas cápsulas que são compostas por diferentes plantas, ervas e árvores que teriam o efeito de reduzir a glicemia.

No que concerne ao uso de fitoterápicos, em geral, ainda se estuda quais poderiam ser os benefícios de plantas e substâncias antivirais naturais no tratamento e prevenção da COVID-19. Entretanto, até o presente momento foram encontrados apenas estudos incipientes, sem que haja comprovação sobre efeitos favoráveis ou tóxicos na utilização dessas plantas e substâncias na prática clínica para tratar a COVID-19.44,45 Portanto, os tópicos que contemplam essa categoria foram classificados como falsos.
A quarta categoria denominada de "COVID-19 e DM" engloba assuntos sobre as duas doenças, tais como: cirurgia metabólica para cura de DM, vacina para COVID-19, o papel das indústrias farmacêuticas que não produzem medicações para doenças como câncer, coronavírus e DM (que possuem cura na visão da notícia veiculada), ineficácia e uso de máscaras, tipo sanguíneo e gravidade da COVID-19, inoculação do vírus em quem tem $\mathrm{DM}$, coronavírus como causador de DM e a origem do vírus.

As notícias sobre vacinas reportam que foram elaboradas vacinas utilizando a técnica de recombinação para cura da DM, no entanto, a vacina existente é destinada unicamente à COVID-19. ${ }^{46}$ Não há descrição na literatura sobre vacinas destinadas ao tratamento ou cura da DM; o que se tem é uma pesquisa que aborda a agricultura molecular como meio de obtenção de moléculas, não especificadas no estudo, que visa ao desenvolvimento de uma vacina oral para o DM tipo 1, feito por meio da recombinação de Ácido Desoxirribonucleico (DNA) com base no vírus da beterraba. ${ }^{47}$

Acerca da utilização e eficiência das máscaras faciais, identificou-se que estas servem como forma de proteção, principalmente em localidades onde o lockdown não é sustentável. Dessa forma, a utilização de máscaras em locais públicos permite uma barreira para o distanciamento físico como uma das medidas de diminuição da propagação do vírus causador da COVID-19. ${ }^{48}$ No que tange ao grupo sanguíneo $A B O$, verificou-se que os indivíduos do grupo $\mathrm{A}$ e do grupo $\mathrm{O}$ apresentaram maior e menor risco, respectivamente, de se infectarem, porém, as informações ainda continuam a ser estudadas. ${ }^{49}$

Sobre o desenvolvimento de DM pós-COVID-19, estudos indicam que esse vírus se liga aos receptores da Enzima Conversora de Angiotensina 2 (ACE2) nas células pancreáticas, o que pode ocasionar uma substancial diminuição da secreção do hormônio insulina. Ademais, há indícios de que a COVID-19 possa danificar as células beta pancreáticas podendo também ocasionar uma grande quantidade de citocinas pró-inflamatórias. ${ }^{50}$ Porém, mais estudos devem ser realizados de maneira a corroborar ou não as informações. Dessa forma, as afirmações de que existem pesquisas que comprovem que a COVID-19 causa DM em pessoas sem histórico prévio da doença anterior ao COVID-19 e de que indivíduos com DM são imunes à referida infecção viral são falsas. Por conseguinte, é igualmente falsa a informação de que o vírus não inocula no sistema imunológico de indivíduos com diabetes.

A última categoria intitulada "gravidade e fatores de risco" compreende as notícias sobre glicose (hiperglicemia), insulina, comorbidades e pneumonia. O comprometimento das células do pâncreas, anteriormente já descrito, pode estar relacionado a quadros de hiperglicemia transitória ou não, observadas em $51 \%$ das pessoas com COVID-19. Entretanto, mais pesquisas precisam ser desenvolvidas para avaliar esses possíveis mecanismos fisiopatológicos,$^{51}$ de maneira a corroborar ou não as informações que afirmam que a COVID-19 causa o estado hiperglicêmico nas pessoas que contraíram a infecção. 
Por conta da redução na quantidade de insulina secretada, algumas pessoas com COVID-19 também apresentaram uma alta resistência à insulina, principalmente aqueles que possuíam doenças graves. Nessa perspectiva, igualmente conclui-se sobre a necessidade de que sejam realizados mais estudos, tendo em vista que não se sabe se essa situação ocorre em decorrência de defeitos nos receptores de insulina nos órgãos principais em associação com o metabolismo da glicose ou se a interferência nos receptores de insulina acontece por meio da sinalização do vírus. ${ }^{52}$

A respeito das comorbidades, uma revisão de literatura identificou diversos fatores clínicos que predispõem a forma grave do curso da COVID-19: a idade avançada e as comorbidades como as doenças cardiovasculares, a doença renal crônica, a doença pulmonar crônica, especialmente a Doença Pulmonar Obstrutiva Crônica (DPOC), a DM, a hipertensão, a imunossupressão, a obesidade e a doença falciforme. Tais condições aumentam as chances de o paciente vir a ser entubado ou ir a óbito. ${ }^{53,54}$

Ainda nessa categoria temática, foi fortemente divulgada a informação de que a COVID-19 pode colaborar para o desenvolvimento imediato de pneumonia. Essa notícia foi classificada como precipitada, pois a COVID-19 pode causar doenças graves do trato respiratório como a Síndrome da Angústia Respiratória Aguda (SARA) e pneumonias, contudo não são todas as pessoas infectadas que desenvolvem esse tipo de complicação. ${ }^{55}$

Por fim, em relação à origem do vírus, acredita-se que ele tenha sido inicialmente transmitido em um mercado chinês, que comercializa animais vivos. Embora a sua origem ainda não tenha sido confirmada, sabe-se que animais como cobras, morcegos e pangolins podem transmitir o SARS-CoV2. ${ }^{55}$

As fake News tem o potencial de influenciar o comportamento da população. Dessa forma, a atuação dos cientistas e profissionais de saúde no combate às fake News é de suma importância, principalmente, ao propor medidas para auxiliar as pessoas e a comunidade a identificar as notícias verdadeiras e as falsas, além de orientar a necessidade de averiguar a informação recebida antes de compartilhá-la. Esforços globais coordenados entre todos os atores envolvidos (organizações de saúde, governos, mídia e indivíduos) devem ser empreendidos para controlar e mitigar os efeitos nocivos das fake news. ${ }^{56,57}$

\section{CONCLUSÃO}

A partir do exposto no presente artigo, observou-se que a maior parte das postagens eram fake news, logo percebe-se o impacto das mídias sociais no que concerne à disseminação de informações, sejam elas verdadeiras ou falsas. Em especial, no contexto da pandemia, constatou-se um excesso de desinformação, dadas as disputas de saberes e poderes. Esse cenário causa um grande prejuízo na comunicação dos órgãos competentes e das comunidades científicas para com a população, dificultando o acesso a informações com embasamento cientifico e, por conseguinte, acarretando em um grande prejuízo na condução do cenário epidemiológico.
A principal limitação do presente estudo está atrelada à análise de apenas três mídias, sendo, portanto, imprescindível a realização de estudos em outras mídias sociais como WhatsApp, Facebook, Instagram e Youtube. Outra limitação foi o recorte temporal de menos de um ano no Twitter, o que pode ter limitado os tipos de notícias veiculadas e dessa maneira ter influenciado nos resultados obtidos.

Entretanto, esses resultados sinalizam a relevância da temática e apontam a necessidade da utilização da comunicação em saúde como ferramenta potente a ser empregada pelos cientistas e profissionais de saúde para dar visibilidade às informações com evidências científicas, de forma acessível e compreensível às pessoas via mídias sociais. Ademais, salienta-se finalmente a importância da comunicação em saúde de maneira a oportunizar a transposição das "ciências" realizadas nas universidades para a comunidade.

\section{CONTRIBUIÇÕES DOS AUTORES}

Desenho do estudo. Thalita da Silva Ribeiro. Angelina Lettiere Viana. Paola Cristina de Castro.

Coleta ou produção dos dados. Thalita da Silva Ribeiro. Gabrielly Stechi.

Análise de dados. Thalita da Silva Ribeiro. Angelina Lettiere Viana. Gabrielly Stechi.

Interpretação dos resultados. Thalita da Silva Ribeiro. Angelina Lettiere Viana.

Redação e revisão crítica do manuscrito. Thalita da Silva Ribeiro. Gabrielly Stechi. Paola Cristina de Castro. Angelina Lettiere Viana.

Aprovação da versão final do artigo. Thalita da Silva Ribeiro. Gabrielly Stechi. Paola Cristina de Castro. Angelina Lettiere Viana.

Responsabilidade por todos os aspectos do conteúdo e a integridade do artigo publicado. Thalita da Silva Ribeiro. Gabrielly Stechi. Paola Cristina de Castro. Angelina Lettiere Viana.

\section{EDITOR ASSOCIADO}

Antonio José de Almeida Filho (D)

\section{EDITOR CIENTÍFICO}

\author{
Ivone Evangelista Cabral (D)
}

\section{REFERÊNCIAS}

1. Ministério da Saúde (BR). Protocolo de manejo clínico do coronavírus (COVID-19) na Atenção Primária à Saúde [Internet]. Brasília: Ministério da Saúde; 2020. [citado 2021 out 12]. Disponível em: https://saude. rs.gov.br/upload/arquivos/202004/14140606-4-ms-protocolomanejoaps-ver07abril.pdf

2. World Health Organization. Coronavirus (COVID-19) dashboard [Internet]. Geneva: WHO; 2021 [citado 2021 set 11]. Disponível em: https://covid19.who.int/

3. Ministério da Saúde (BR). COVID-19 no Brasil. [Internet]. Brasília: Ministério da Saúde; 2020 [citado 2021 nov 08]. Disponível em: https:// qsprod.saude.gov.br/extensions/covid-19_html/covid-19_html.html 
4. Sociedade Brasileira de Diabetes. Notas de esclarecimentos da Sociedade Brasileira de Diabetes sobre o coronavírus (COVID-19) [Internet]. São Paulo: SBD; 2020 [citado 2021 jul 29]. Disponível em: https://www.diabetes.org.br/covid-19/notas-de-esclarecimentos-dasociedade-brasileira-de-diabetes-sobre-o-coronavirus-covid-19/.

5. Wu C, Chen X, Cai Y, Xia J, Zhou X, Xu S et al. Risk factors associated with acute respiratory distress syndrome and death in patients with coronavirus disease 2019 pneumonia in Wuhan, China. JAMA Intern Med. 2020;180(7):934-43. http://dx.doi.org/10.1001/jamainternmed.2020.0994. PMid:32167524.

6. Ministério da Saúde (BR). Guia de vigilância epidemiológica: emergência de saúde pública de importância nacional pela doença pelo coronavírus 2019. Vigilância integrada de síndromes respiratórias agudas doença pelo coronavírus 2019, influenza e outros vírus respiratórios [Internet]. Brasília: Ministério da Saúde; 2020. [citado 2021 ago 05]. Disponível em https://portaldeboaspraticas.iff.fiocruz.br/biblioteca/guia-de-vigilanciaepidemiologica-emergencia-de-saude-publica-de-importancia-nacional/.

7. Landstra CP, Koning EJP. COVID-19 and Diabetes: understanding the interrelationship and risks for a severe course. Front Endocrinol. 2021;12:649525. http://dx.doi.org/10.3389/fendo.2021.649525. PMid:34220706.

8. Falcão $P$, Souza $A B$. Pandemia de desinformação: as fake news no contexto da Covid-19 no Brasil. RECIIS. 2021;15(1):55-71. http://dx.doi. org/10.29397/reciis.v15i1.2219.

9. Neto M, Gomes TO, Porto FR, Rafael RMR, Fonseca MHS, Nascimento J. Fake news no cenário da pandemia de Covid-19. Cogitare Enferm. 2020;25. http://dx.doi.org/10.5380/ce.v25i0.72627.

10. Silva MAR, Melo SA. Fake news: fronteiras do jornalismo e circulação de (des)informação sobre saúde. RECIIS. 2020;14(1):1-5. http://dx.doi. org/10.29397/reciis.v14i1.2047.

11. Hua J, Shaw R. Corona Virus (COVID-19) "infodemic" and emerging issues through a data lens: the case of China. Int J Environ Res Public Health. 2020;17(7):2309. http://dx.doi.org/10.3390/ijerph17072309. PMid:32235433.

12. Zarocostas J. How to fight an infodemic. Lancet. 2020;395(10225):676 http://dx.doi.org/10.1016/S0140-6736(20)30461-X. PMid:32113495.

13. Organização Pan-Americana da Saúde. Entenda a infodemia e a desinformação na luta contra a COVID-19. Brasil: OPAS/OMS [Internet]. Brasília: OPAS; 2020 [citado 2021 nov 03]. Disponível em https://iris. paho.org/bitstream/handle/10665.2/52054/Factsheet-Infodemic_por. pdf? sequence $=16$

14. Freire NP, Cunha ICKO, Ximenes No FRG, Machado MH, Minayo MCS. A infodemia transcende a pandemia. Cien Saude Colet. 2021;26(9):40658. http://dx.doi.org/10.1590/1413-81232021269.12822021.

15. Posetti J, Bontcheva K. Desinfodemia: decifrar a desinformação sobre a COVID-19 [Internet]. Paris: UNESCO; 2020 [citado 2021 nov 03] Disponivel em: https://unesdoc.unesco.org/ark:/48223/pf0000374416_por

16. Ministério da Saúde (BR). Saúde sem fake news [Internet]. Brasil: Ministério da Saúde; 2021 [citado 2021 nov 06]. Disponível em: https:// antigo.saude.gov.br/fakenews/

17. Secosan I, Virga D, Crainiceanu ZP, Bratu LM, Bratu T. Infodemia: another enemy for romanian frontline healthcare workers to fight during the COVID-19 outbreak. Medicina. 2020;56(12):679. http://dx.doi. org/10.3390/medicina56120679. PMid:33317190.

18. Mattos AM, Costa IZK, Neto M, Rafael RMR, Carvalho EC, Porto F Fake News em tempos de COVID-19 e seu tratamento jurídico no ordenamento brasileiro. Esc Anna Nery. 2021;25(spe):e20200521. http://dx.doi.org/10.1590/2177-9465-ean-2020-0521.

19. Marconi MA, Lakatos EM. Fundamentos de metodologia científica. São Paulo: Editora Atlas; 2003

20. Prodanov CC, Freitas EC. Metodologia do trabalho científico: métodos e técnicas da pesquisa e do trabalho acadêmico. Novo Hamburgo: Editora Feevale; 2013

21. Atehortua NA, Patino S. COVID-19, a tale of two pandemics: novel coronavirus and fake news messaging. Health Promot Int.2021;36(2):52434. http://dx.doi.org/10.1093/heapro/daaa140. PMid:33450022.
22. Sociedade Brasileira de Diabetes. Diabetes na era COVID-19 [Internet] São Paulo: SBD; 2020 [citado 2020 out 29]. Disponível em: https:// diabetes.org.br/covid-19/

23. Sociedade Brasileira de Diabetes. Notas de esclarecimentos da Sociedade Brasileira de Diabetes sobre o coronavírus (COVID-19) [Internet]. São Paulo: SBD;2020 [citado 2021 out 20]. Disponível em: https://diabetes. org.br/covid-19/notas-de-esclarecimentos-da-sociedade-brasileira-dediabetes-sobre-o-coronavirus-covid-19/

24. Sociedade Brasileira de Diabetes. Perguntas frequentes [Internet]. São Paulo: SBD;2020. [citado 2021 out 21]. Disponível em: https://diabetes. org.br/covid-19/perguntas-frequentes/

25. Ministério da Saúde (BR). Coronavírus fake news [Internet]. Brasil: Ministério da Saúde;2021. [citado 2021 nov 05]. Disponível em: https:// antigo.saude.gov.br/fakenews/

26. Gomes R. Análise e interpretação de dados de pesquisa qualitativa In: Minayo MCS, Deslandes SF, Gomes R, organizadores. Pesquisa social: teoria, método e criatividade. Petrópolis: Vozes; 2018. p. 72-95

27. Mheidly N, Fares J. Leveraging media and health communication strategies to overcome the COVID-19 infodemic. J Public Health Policy. 2020;41(4):410-20. http://dx.doi.org/10.1057/s41271-020-00247-w. PMid:32826935.

28. Lewandowsky S, Ecker UKH, Seifert CM, Schwarz N, Cook J. Misinformation and its correction: continued influence and successful debiasing. Psychol Sci Public Interest. 2012 dez;13(3):106-31. http:// dx.doi.org/10.1177/1529100612451018. PMid:26173286.

29. França T, Rabello ET, Magnago C. As mídias e as plataformas digitais no campo da Educação Permanente em Saúde: debates e propostas. Saúde Debate. 2019;43(spe1):106-15. http://dx.doi.org/10.1590/010311042019 s109.

30. Giordani RCF, Donasolo JPG, Ames VDB, Giordani RL. A ciência entre a infodemia e outras narrativas da pós-verdade: desafios em tempos de pandemia. Cien Saude Colet. 2021;26(7):2863-72. http://dx.doi. org/10.1590/1413-81232021267.05892021.

31. Sousa Júnior JH, Raasch M, Soares JC, Ribeiro LVHAS. Da desinformação ao caos: uma análise das Fake News frente à pandemia do Coronavírus (COVID-19) no Brasil. Cadernos de Prospecção. 2020;13(2):331-46. http://dx.doi.org/10.9771/cp.v13i2\%20COVID-19.35978.

32. Caetano K, Nishida L, Tavares R, Koster I. Desafios para o trabalho da disseminação científica em saúde pública em contexto de disseminação do coronavírus. RECIIS. 2021;15(1):233-48. http://dx.doi.org/10.29397/ reciis.v15i1.2202.

33. Vellingiri B, Jayaramayya K, lyer M, Narayanasamy A, Govindasamy V, Giridharan B et al. COVID-19: a promising cure for the global panic Sci Total Environ. 2020;725:138277. http://dx.doi.org/10.1016/j. scitotenv.2020.138277. PMid:32278175

34. Anil SM, Shalev N, Vinayaka AC, Nadarajan S, Namdar D, Belausov E et al. Cannabis compounds exhibit anti-inflammatory activity in vitro in COVID-19-related inflammation in lung epithelial cells and proinflammatory activity in macrophages. Sci Rep. 2021;11(1):1462. http:// dx.doi.org/10.1038/s41598-021-81049-2. PMid:33446817.

35. Bae M, Kim H. Mini-Review on the Roles of Vitamin C, Vitamin D, and Selenium in the Immune System against COVID-19. Molecules. 2020;25(22):5346. http://dx.doi.org/10.3390/molecules25225346. PMid:33207753.

36. Maddaloni E, Cavallari I, Napoli N, Conte C.Vitamin D and Diabetes Mellitus. Front Horm Res. 2018;50:161-76. http://dx.doi.org/10.1159/000486083. PMid:29597238.

37. Estrela FM, Soares CFS, Cruz MA, Silva AF, Santos JRL, Moreira TMO et al. Covid-19 pandemic: reflecting vulnerabilities in the light of gender, race and class. Cien Saude Colet. 2020;25(9):3431-6. http:// dx.doi.org/10.1590/1413-81232020259.14052020. PMid:32876261.

38. Figueiredo AM, Figueiredo DCMM, Gomes LB, Massuda A, GilGracía E, Vianna RPT. Social determinants of health and COVID-19 infection in Brazil: an analysis of the pandemic. Rev Bras Enferm. 2020;73(Suppl2):e20200673. http://dx.doi.org/10.1590/0034-71672020-0673. PMid:33206820.

39. Hashmi FK, Iqbal Q, Haque N, Saleem F. Religious cliché and stigma: a brief response to overlooked barriers in COVID-19 management. $J$ 
Relig Health. 2020;59(6):2697-700. http://dx.doi.org/10.1007/s10943020-01063-y. PMid:32643082.

40. Reynolds HR, Adhikari S, Pulgarin C, Troxel AB, Iturrate E, Johnson $\mathrm{SB}$ et al. Renin-angiotensin-aldosterone system inhibitors and risk of Covid-19. N Engl J Med. 2020;382(25):2441-8. http://dx.doi.org/10.1056/ NEJMoa2008975. PMid:32356628.

41. Majumder J, Minko T. Recent developments on therapeutic and diagnostic approaches for COVID-19. AAPS J. 2021;23(1):14. http:// dx.doi.org/10.1208/s12248-020-00532-2. PMid:33400058.

42. Stoian AP, Catrinoiu D, Rizzo M, Ceriello A. Hydroxychloroquine, COVID-19 and diabetes. Why it is a different story. Diabetes Metab Res Rev. 2021;37(2):e3379. http://dx.doi.org/10.1002/dmrr.3379. PMid:32592507.

43. Cortegiani A, Ingoglia G, Ippolito M, Giarratano A, Einav S. A systematic review on the efficacy and safety of chloroquine for the treatment of COVID-19. J Crit Care. 2020;57:279-83. http://dx.doi.org/10.1016/j. jcrc.2020.03.005. PMid:32173110.

44. Komolafe K, Komolafe TR, Fatoki TH, Akinmoladun AC, Brai BIC, Olaleye MT et al. Coronavirus disease 2019 and herbal therapy: pertinent issues relating to toxicity and standardization of phytopharmaceuticals. Rev Bras Farmacogn. 2021;11:1-20. http://dx.doi.org/10.1007/s43450-02100132-x. PMid:33727754.

45. Gour A, Manhas D, Bag S, Gorain B, Nandi U. Flavonoids as potential phytotherapeutics to combat cytokine storm in SARS-CoV-2. Phytother Res. 2021;35(8):4258-83. http://dx.doi.org/10.1002/ptr.7092. PMid:33786876.

46. LiverTox. LiverTox: clinical and research information on drug-induced liver injury [Internet]. Bethesda: National Institute of Diabetes and Digestive and Kidney Diseases; 2012 [citado 2021 nov 05]. Disponível em: https://www.ncbi.nlm.nih.gov/books/NBK570468/

47. Santoni M, Bertini E, Zampieri R, Cuccurullo A, Commisso M, Gecchele E et al. Transient expression in red beet of a biopharmaceutical candidate vaccine for Type-1 Diabetes. JVis Exp. 2019;(145):e59298. http://dx.doi. org/10.3791/59298. PMid:30958463.

48. Esposito S, Principi N, Leung CC, Migliori GB. Universal use of face masks for success against COVID-19: evidence and implications for prevention policies. Eur Respir J. 2020;55(6):2001260. http://dx.doi. org/10.1183/13993003.01260-2020. PMid:32350103.

49. Muñiz-Diaz E, Llopis J, Parra R, Roig I, Ferrer G, Grifols J et al. Relationship between the $A B O$ blood group and COVID-19 susceptibility, severity and mortality in two cohorts of patients. Blood Transfus. 2021;19(1):54-63. http://dx.doi.org/10.2450/2020.0256-20. PMid:33196417.

50. Heaney Al, Griffin GD, Simon EL. Newly diagnosed diabetes and diabetic ketoacidosis precipitated by COVID-19 infection. Am J Emerg Med. 2020;38(11):2491.e3-4. http://dx.doi.org/10.1016/j.ajem.2020.05.114. PMid:32536476.

51. Ilias I, Zabuliene L. Hyperglycemia and the novel Covid-19 infection: possible pathophysiologic mechanisms. Med Hypotheses. 2020;139:109699. http://dx.doi.org/10.1016/j.mehy.2020.109699. PMid:32240876.

52. Sathish T, Kapoor N, Cao Y, Tapp RJ, Zimmet P. Proportion of newly diagnosed diabetes in COVID-19 patients: a systematic review and meta-analysis. Diabetes Obes Metab. 2021;23(3):870-4. http://dx.doi. org/10.1111/dom.14269. PMid:33245182.

53. Marin BG, Aghagoli G, Lavine K, Yang L, Siff EJ, Chiang SS et al Predictors of COVID-19 severity: a literature review. Rev Med Virol. 2021;31(1):1-10. http://dx.doi.org/10.1002/rmv.2146. PMid:32845042.

54. Li X, Xu S, Yu M, Wang K, Tao Y, Zhou Y et al. Risk factors for severity and mortality in adult COVID-19 inpatients in Wuhan. J Allergy Clin Immunol.2020;146(1):110-8. http://dx.doi.org/10.1016/j.jaci.2020.04.006. PMid:32294485.

55. Ahn DG, Shin HJ, Kim MH, Lee S, Kim HS, Myoung J et al. Current status of epidemiology, diagnosis, therapeutics, and vaccines for Novel Coronavirus Disease 2019 (COVID-19). J Microbiol Biotechnol. 2020;30(3):313-24. http://dx.doi.org/10.4014/jmb.2003.03011. PMid:32238757.

56. Barcelos TN, Muniz LN, Dantas DM, Cotrim Jr DF, Cavalcante JR, Faerstein E. Análise de fake news veiculadas durante a pandemia de COVID-19 no Brasil. Rev Panam Salud Publica. 2021;45:e65. http:// dx.doi.org/10.26633/RPSP.2021.65. PMid:34007263.

57. Domingues L. Infodemic: a threat to global public health during and after the Covid-19 pandemic. RECIIS. 2021;15(1):12-7. http://dx.doi. org/10.29397/reciis.v14i4.2237. 


\section{Errata: Comunicação em saúde sobre COVID-19 e Diabetes Mellitus em mídias sociais: verdadeiro e falso}

\section{Erratum: Health communication about COVID-19 and Diabetes Mellitus in social media: True and False}

No artigo "Comunicação em saúde sobre COVID-19 e Diabetes Mellitus em mídias sociais: verdadeiro e falso", DOI número: 10.1590/2177-9465-EAN-2021-0358, publicado em Escola Anna Nery Revista de Enfermagem 2022;26(spe):e20210358, no quadro 1 onde lia-se:

Quadro 1. Relação de assuntos Fake News encontradas em três plataformas de veiculação de informações. Ribeirão Preto, São Paulo, Brasil, 2021

\begin{tabular}{|c|c|c|c|}
\hline \multirow{2}{*}{ Categoria Temática } & \multirow{2}{*}{ Notícia } & \multicolumn{2}{|c|}{ Mídia } \\
\hline & & MS & Twitter \\
\hline \multirow{8}{*}{ Alimentos e substâncias } & Receita de coco que cura coronavírus & $\mathrm{X}$ & \\
\hline & $\begin{array}{l}\text { A vitamina } D \text { também ajuda a prevenir diabetes, ataque cardíaco e derrame. As pessoas que morreram com o Coronavírus } \\
\text { tinham deficiência de vitamina } D\end{array}$ & & $\mathrm{X}$ \\
\hline & $\begin{array}{l}\text { Eu juro, pelo que tenho "ouvido", água de coco é a resposta para: diabetes, doença renal, doença hepática, hipertensão, } \\
\text { controlar o colesterol, coronavírus, droga: encontramos o elixir da vida! }\end{array}$ & & $\mathrm{X}$ \\
\hline & Café previne o coronavírus & $\mathrm{x}$ & \\
\hline & Chá de limão com bicarbonato quente cura coronavírus & $\mathrm{x}$ & \\
\hline & Óleo consagrado para curar coronavírus & $\mathrm{x}$ & \\
\hline & Vitamina C cura coronavírus, que veio dos animais, e água com limão que cura câncer & $\mathrm{x}$ & \\
\hline & Vídeo - vitamina D e a prevenção do novo coronavírus & $\mathrm{x}$ & \\
\hline $\begin{array}{l}\text { Condição socioeconômica } \\
\text { e hábitos de vida }\end{array}$ & Tanto o coronavírus quanto o diabetes são doenças de alto poder aquisitivo & & $\mathrm{X}$ \\
\hline
\end{tabular}

Leia-se:

Quadro 1. Relação de assuntos em dois canais de veiculação de informações (Twitter e Ministério da Saúde - MS) classificadas como falsas tanto pelo Ministério da Saúde quanto pela literatura científica. Ribeirão Preto, São Paulo, Brasil, 2021

\begin{tabular}{|c|c|}
\hline Categoria Temática & Notícia \\
\hline \multirow{8}{*}{ Alimentos e substâncias } & Receita de coco que cura coronavírus (MS) ${ }^{(45,46)}$ \\
\hline & $\begin{array}{l}\text { A vitamina D também ajuda a prevenir diabetes, ataque cardíaco e derrame. As pessoas que morreram com o Coronavírus tinham deficiência de vitamina } \\
\text { D (Twitter) }{ }^{(35,36)}\end{array}$ \\
\hline & $\begin{array}{l}\text { Eu juro, pelo que tenho "ouvido", água de coco é a resposta para: diabetes, doença renal, doença hepática, hipertensão, controlar o colesterol, } \\
\text { coronavírus, droga: encontramos o elixir da vida! (Twitter) }{ }^{(45,46)}\end{array}$ \\
\hline & Café previne o coronavírus (MS) ${ }^{(45,46)}$ \\
\hline & Chá de limão com bicarbonato quente cura coronavírus (MS) ${ }^{(45,46)}$ \\
\hline & Óleo consagrado para curar coronavírus (MS) $)^{(39)}$ \\
\hline & Vitamina C cura coronavírus, que veio dos animais, e água com limão que cura câncer (MS) ${ }^{(35,36)}$ \\
\hline & Vídeo - vitamina D e a prevenção do novo coronavírus (MS) $)^{(35,36)}$ \\
\hline $\begin{array}{l}\text { Condição socioeconômica } \\
\text { e hábitos de vida }\end{array}$ & Tanto o coronavírus quanto o diabetes são doenças de alto poder aquisitivo (Twitter) $(37,38)$ \\
\hline \multirow{3}{*}{ Medicações } & Medicamento para COVID-19 (criação de medicamento) (MS) ${ }^{(43,44)}$ \\
\hline & Cloroquina cura coronavírus, lassa, HIV, diabetes, hipertensão e febre (twitter) ${ }^{(43,44)}$ \\
\hline & Medicamentos tomados por milhares de pessoas com hipertensão e diabetes podem aumentar o risco de sintomas mortais do coronavírus (Twitter) ${ }^{(40,41)}$ \\
\hline \multirow{4}{*}{ COVID-19 e DM } & As evidências sugerem que o coronavírus pode causar diabetes (Twitter) ${ }^{(51,52,53)}$ \\
\hline & $\begin{array}{l}\text { A cirurgia metabólica se posiciona como a melhor opção para a cura do diabetes associado à obesidade, doenças que representam fatores de risco } \\
\text { para infecção por coronavírus (Twitter) }{ }^{(51,52,53)}\end{array}$ \\
\hline & Máscaras sem qualidade distribuídas pelo Ministério da Saúde (MS) $)^{(49)}$ \\
\hline & $\begin{array}{l}\text { Criaram um vírus seletivo, coronavírus chinês, para resolver problema da superpopulação de idosos e das pessoas com doenças como diabetes } \\
\text { hipertensão cardíacos etc (Twitter)(56) }\end{array}$ \\
\hline \multirow{6}{*}{$\begin{array}{l}\text { Gravidade e fatores de } \\
\text { risco }\end{array}$} & Aqueles que morreram como resultado do coronavírus são os idosos, aqueles com doenças crônicas como diabetes, insuficiência renal crônica etc. \\
\hline & A máscara não é particularmente útil por causa da umidade da respiração (para que isso seja útil, você precisa trocar a máscara a cada 30 minutos) \\
\hline & $(\text { Twitter })^{54,55)}$ \\
\hline & Coronavírus não pega diabetes. É contra a lei (Twitter) $^{(51,52,53)}$ \\
\hline & Médicos tailandeses curam coronavírus em $48 \mathrm{~h}(\mathbf{M S})^{(33,42)}$ \\
\hline & Novo coronavírus causa pneumonia de imediato (MS) ${ }^{(54,55)}$ \\
\hline
\end{tabular}

Fonte: notícias adaptadas da plataforma Twitter e $\mathrm{MS}^{25}$ 
No artigo "Comunicação em saúde sobre COVID-19 e Diabetes Mellitus em mídias sociais: verdadeiro e falso”, DOI número: 10.1590/2177-9465-EAN-2021-0358, publicado em Escola Anna Nery Revista de Enfermagem 2021;26(SpeCovid19):e20210358, no quadro 1 onde lia-se:

\section{CONCLUSÃO}

A partir do exposto no presente artigo, observou-se que a maior parte das postagens eram fake news, logo percebe-se o impacto das mídias sociais no que concerne à disseminação de informações, sejam elas verdadeiras ou falsas. Em especial, no contexto da pandemia, constatou-se um excesso de desinformação, dadas as disputas de saberes e poderes. Esse cenário causa um grande prejuízo na comunicação dos órgãos competentes e das comunidades científicas para com a população, dificultando o acesso a informações com embasamento cientifico e, por conseguinte, acarretando em um grande prejuízo na condução do cenário epidemiológico.

A principal limitação do presente estudo está atrelada à análise de apenas três mídias, sendo, portanto, imprescindível a realização de estudos em outras mídias sociais como WhatsApp, Facebook, Instagram e Youtube. Outra limitação foi o recorte temporal de menos de um ano no Twitter, o que pode ter limitado os tipos de notícias veiculadas e dessa maneira ter influenciado nos resultados obtidos.

Entretanto, esses resultados sinalizam a relevância da temática e apontam a necessidade da utilização da comunicação em saúde como ferramenta potente a ser empregada pelos cientistas e profissionais de saúde para dar visibilidade às informações com evidências científicas, de forma acessível e compreensível às pessoas via mídias sociais. Ademais, salienta-se finalmente a importância da comunicação em saúde de maneira a oportunizar a transposição das "ciências" realizadas nas universidades para a comunidade.

Leia-se:

\section{CONCLUSÃO}

A partir do exposto no presente artigo, observou-se que a maior parte das postagens analisadas nos canais de veiculação de informações (Twitter e Ministério da Saúde) versavam sobre conteúdos caracterizados como fake news, logo percebe-se o impacto das mídias sociais no que concerne à disseminação de informações, sejam elas verdadeiras ou falsas. Em especial, no contexto da pandemia, constatou-se um excesso de desinformação, dadas as disputas de saberes e poderes. Esse cenário causa um grande prejuízo na comunicação dos órgãos competentes e das comunidades científicas para com a população, dificultando o acesso a informações com embasamento cientifico e, por conseguinte, acarretando em um grande prejuízo na condução do cenário epidemiológico.

A principal limitação do presente estudo está atrelada à análise de apenas duas mídias, sendo, portanto, imprescindível a realização de estudos em outras mídias sociais como WhatsApp, Facebook, Instagram e YouTube. Outra limitação foi o recorte temporal de menos de um ano no Twitter, o que pode ter limitado os tipos de notícias veiculadas e dessa maneira ter influenciado nos resultados obtidos. Ademais, reconhece-se que as buscas por estudos científicos acerca da temática ocorreram em um período onde pode-se observar um grande quantitativo de publicações e estudos ainda preliminares relacionados a temática deste estudo.

Entretanto, os resultados deste estudo sinalizam para a relevância da temática e apontam a necessidade da utilização da comunicação em saúde como ferramenta potente a ser empregada pelos cientistas e profissionais de saúde para dar maior visibilidade às informações com evidências científicas, de forma acessível e compreensível às pessoas via mídias sociais conforme o trabalho realizado pelas entidades e órgãos competentes. Salientando-se assim, a importância da comunicação em saúde de maneira a oportunizar a transposição das "ciências" realizadas nas universidades para a comunidade. 